University of Washington Tacoma

UW Tacoma Digital Commons

SIAS Faculty Publications

School of Interdisciplinary Arts and Sciences

$11-26-2018$

\title{
Mothers Do Not Make Good Workers: The Role of Work/Life Balance Policies in Reinforcing Gendered Stereotypes
}

Sarah Cote Hampson

University of Washington Tacoma, hampsons@uw.edu

Follow this and additional works at: https://digitalcommons.tacoma.uw.edu/ias_pub

\section{Recommended Citation}

Hampson, Sarah Cote, "Mothers Do Not Make Good Workers: The Role of Work/Life Balance Policies in Reinforcing Gendered Stereotypes" (2018). SIAS Faculty Publications. 1019.

https://digitalcommons.tacoma.uw.edu/ias_pub/1019

This Article is brought to you for free and open access by the School of Interdisciplinary Arts and Sciences at UW Tacoma Digital Commons. It has been accepted for inclusion in SIAS Faculty Publications by an authorized administrator of UW Tacoma Digital Commons. 


\title{
Mothers Do Not Make Good Workers: \\ The Role of Work/Life Balance Policies in Reinforcing Gendered Stereotypes ${ }^{1}$
}

Sarah Cote Hampson, University of Washington Tacoma

\begin{abstract}
"Family friendly" policies such as maternity leave allow millions of women in the U.S. to take some time off when they give birth or adopt a child in order to spend time physically recuperating and/or initiating a bond with their children. However, many working mothers report facing stereotypes that either negatively impact their decision-making about claiming their rights under work/life balance policies, or cause them to be the specific targets of discrimination in their workplaces. This article, which draws upon in-depth interviews with 48 women from two types of work environments (the U.S. military and academia), identifies stereotypes that have developed in these institutions. These stereotypes establish the identity of a working mother as the antithesis of an "ideal worker". I argue that the very policies that are aimed at easing the tension between work and family help to create and reinforce these stereotypes through discursive institutional processes.
\end{abstract}

Keywords: Gender; law; working mothers; ideal worker; stereotypes; limits of the law 


\section{Introduction}

Millions of women in the U.S. take some time off when they give birth or adopt a child using "family friendly" laws and policies in order to spend time recuperating and/or to initiate a bond with their children. Such allowances are grounded in federal law (The Family and Medical Leave Act of 1992), state and municipal laws (e.g. California's Paid Family Leave Law of 2002, or the City of Seattle's 2015 introduction of paid parental leave for city employees), and individual institutional policies. In recent years, another wave of policies aimed at improving the rate of breastfeeding among working mothers have also taken hold throughout various states. A provision in the Affordable Care Act has brought similar accommodation requirements to federal laws, ${ }^{1}$ and many workplaces have gone above and beyond state and federal requirements and have implemented multiple lactation rooms and on-site support services.

Policies that aim to improve work/life balance are often created with the hope that changes in structural support for women in the workplace will allow for social changes to also take effect at work. Activists and policymakers hope that such policy changes will not only increase women's participation in the workplace, but also help women to experience greater overall equity as workers. These policies, however, have thus far fallen short of fully alleviating the tensions that women across the nation are still grappling with as they try to balance their

\footnotetext{
${ }^{1}$ After the passage of the Affordable Care Act, Section $7(r)$ of the Fair Labor Standards Act was amended to require that employers with 50 or more employees give their employees "reasonable break time" to express breast milk for the first year after a child's birth "each time such employee has need to express" as well as the provision of "a place, other than a bathroom, that is shielded from view" to express milk (https://www.dol.gov/whd/nursingmothers/Sec7rFLSA btnm.htm). Breastfeeding policies such as these are cited by women as important for their ability to follow the advice of healthcare professionals that it is ideal to provide infants with breastmilk for the first six months of their life (American Academy of Pediatrics 2012).
} 
work and their family responsibilities. ${ }^{2}$ A recent Pew Research Center survey shows, for instance, that mothers are still far more likely to experience a career interruption than fathers in order to fulfill caregiving work. The study notes that 42 percent of mothers have reduced their working hours in order to care for a child or family member, compared with 28 percent of men, and 27 percent of women reported having quit their job to perform these caregiving tasks, compared with just 10 percent of men) (Cohn et al. 2014). Another Pew survey shows that 41 percent of working mothers report that being a mother makes it harder to advance in their careers, compared with just 20 percent of working fathers who said the same (Pew Research Center 2015).

Women are also continuing to experience cultural stereotypes at work. Heilman and Chen find that in psychological experiments, women are viewed 14 percent less positively than men if they volunteer to stay late and work on a project and 12 percent more negatively than men if they do not (Heilman and Chen 2005). Moreover, Williams and Dempsey note that even women in high-earning professions such as law and medicine continue to be consigned to the "office housework" that includes planning parties, ordering food, and doing other undervalued, administrative tasks (Williams and Dempsey 2014). These studies reveal that there is essentially a gap between the changes in public policy over the last twenty-five years or so and the degree to which women feel the impact of these policies in their own lives.

\footnotetext{
${ }^{2}$ It is for this reason that I focus on "mothers" in contrast with non-mothers in this research. While not wishing to provide an essential definition for "woman" or "mother" in this study, I do think that the data which points to an ongoing marginalization of "women" and "mothers" in U.S. society means that an emphasis on "mothers" rather than "parents" is warranted. However, I also acknowledge that by homogenizing the term "mother" these data and others are masking the very real differences between and among women and others who identify as doing the care work often described as "mothering".
} 
Law and Society scholars have long interrogated the "gap" between the law on the books and the law in action, and the role of the law in bringing about social change. It is therefore within the context of this literature that I expound on the disconnect between advances in "family friendly" public policies and the lived experiences of working mothers. This article draws upon in-depth interviews with 48 women from two types of work environments: the U.S. military and academia. I apply Law and Society conversations about work and identity to the topic of working mothers. I explore the discourses that have arisen within institutional settings that are salient to the way that women think about their own identities as workers - and about their rights under federal, state and workplace work/life balance policies.

In what follows, I review the sociolegal literature that has already made significant headway in connecting law, discourse and identity - particularly within workplace settings - as a means of explaining gaps between the law on the books and the law in action. I then connect this discussion to a broader literature that has recognized and documented the significance of an "ideal worker" construct within institutional settings. This discussion of the literature on law, discourse and identity and in particular the formation of an "ideal worker" construct serve as the basis for what follows. I next introduce the empirical element of this analysis, which documents the existence of ideal worker-types in both academia and the U.S. military. I demonstrate that these ideal worker types within each workplace setting serve to establish and reinforce stereotypes of female workers within these institutions - stereotypes that set female workers in stark contrast to the ideal worker types. In the final section of this paper, I argue that these stereotypes - far from being allayed by work/life balance laws and policies - are often, in fact, reinforced and compounded by them. Indeed, this study reveals that the very policies aimed at 
increasing working mothers' workforce participation and retention can often reinforce damaging cultural stigmas of women as non-ideal workers.

\section{Law, Discourse and the "Ideal Worker"}

David Engel and Frank Munger's (2003) seminal work on the connection between rights and identity in the workplace traces the impact of the Americans with Disabilities Act (ADA) on individuals' legal consciousness. Their study reveals the complex relationship between law and the way that individuals think about, internalize and appropriate law. Through interviews with disabled workers, the authors demonstrate how these individuals engage with rights through their definition or re-definition of their individual identities - specifically in the context of work. Identity and paid employment are fundamentally linked, the authors claim, and laws such as the ADA seek to transform, not just the physical structure of the workplace for those with disabilities, but the social presumptions that undergird their very "disabled-ness". Rights, the authors argue, by permeating cultural norms and everyday discourse, can transform how individuals view themselves under the law, and also how others view them as individuals.

Legal consciousness, and its formation, is an important concept in Engel and Munger's work. Legal consciousness is essentially the way that individuals use the law and legal concepts to interpret the world around them, and their own lives and identities. Legal consciousness can impact individuals' thoughts, language and actions. Significantly, legal consciousness can also impact how individuals choose to use (or not use) the law (Engel 1984; McCann 1994; Ewick and Silbey 1998; Morgan 1999; Gilliom 2001; Haltom and McCann 2004; Marshall 2005). Therefore, the process by which individuals come to form this legal consciousness is a significant one, worthy of investigation. Engel and Munger define the development of legal 
consciousness as a two-way process, "through which the self continually evolves and redefines the relevance or irrelevance of law" $(2003,13)$.

William Haltom and Michael McCann (2004) also examine the formation of legal consciousness using a process-based approach. In their study of the politics of tort reform, the authors look closely at the role of discourse in shaping legal consciousness. Haltom and McCann's study demonstrates the recursive role of media institutions, elites, and ideology in shaping public discourse, and thus public consciousness around litigiousness in America. Other sociolegal scholars have also highlighted the significant role of discourse within institutional settings in shaping cultural norms and informal and formal legal systems (Ewick and Silbey 1998; Albiston 1995, 2010; Engel and Munger 2003; Marshall and Barclay 2003; Marshall 2005).

Discourse plays an important role within institutional settings in shaping both legal consciousness and individual identity. Its effect on legal consciousness and identity is important, because research has overwhelmingly shown the significance of individuals' subjective cognitive processes in the effective mobilization of rights. The impact of law and policies that establish individual rights, in other words, is limited by the power of informal norms, power relations, social interactions and institutional constraints (Albiston 2010; Quinn 2000; Scheingold 2004; McCann 1994; Bumiller 1987; Ewick and Silbey 1998; Marshall 2003, 2005; Gruber 1998; Williams and Cooper 2004). Catherine Albiston, for instance, finds that women have difficulty mobilizing their right to FMLA leave, because "workplace rights mobilization remains embedded within existing practices, deeply held beliefs, and taken-for-granted expectations about work, gender, and disability, all of which can create subtle but persistent resistance to these new rights" $(2010,181)$. In summary, sociolegal scholars have well documented the significant 
role that informal schemas and norms can play in nullifying rights or rights-granting polices. Furthermore, these scholars have shown in other contexts that such informal norms can often make it extremely difficult for individuals to claim their rights within institutional settings.

Several scholars, most notably Joan Williams, have documented the existence of an ideal worker concept within workplace contexts (Berns 2002; Williams 2000, 2009; Williams and Cooper 2004; Kessler-Harris 2001; Kelly et al. 2010). Williams (2000) in particular has argued for its detrimental effects on women's decisions to seek out or take up maternity leave rights. In Unbending Gender, she argues that both men and women face challenges posed by the notion of the ideal worker, which she claims is pervasive in American workplace culture. The ideal worker is childless or has an invisible caretaker at home, looking after domestic considerations and care needs so that the worker need not be concerned with these things. He or she is able to work full time and overtime, anytime. The ideal worker does not take maternity leave or need to pick up a sick child from school. The notion of the ideal worker, in other words, presents a dichotomy between "good" workers as those who are entirely devoted to their jobs and "bad" workers as those whose time and attention is consistently pulled to things outside work.

The ideal worker norm did not emerge from thin air. Rather, Williams argues, it is part of a larger ideology, which she calls an "ideology of domesticity." Williams documents how this ideology is both historically and still pervasive in American thought, culture, and law. ${ }^{3}$ Susan Moller Okin is a feminist theorist who tackles the history of this ideology head-on, arguing that

3 For instance, Williams (2000) cites a Washington Post poll from 1998 indicating that two-thirds of Americans believe it would be better for women to stay home and care for family and children. Yet this ideology is not time-bound. In a Pew Center study twelve years later, 37 percent of respondents said that "mothers of young children working outside the home" is a "bad thing for society" while only 27 percent of respondents said it is a "good thing for society" (Taylor et al. 2010). 
liberal theorists have long ignored women, relegating them to a "private" sphere that is irrelevant to the political or "public" sphere. It is the ideological separation of these two spheres that is the primary source of continued injustice for women, argues Okin (1991)

Yet the ideology and practice of domesticity remain intimately connected in American culture and politics. Several feminist scholars point to the significant connection between gender and caregiving expectations in the American workplace. Martha Albertson Fineman's work, for instance, emphasizes cultural ambivalence toward the strong caregiving ties of many women in the United States, arguing that it is this bond that should in fact be recognized by law and society as the nuclear family rather than the sexual bond of man and wife (1995) Laura T. Kessler follows in Fineman's footsteps and looks specifically at the traditional role of caregiver that a large percentage of women still carry out in their private spheres, arguing that law and legal tradition have systematically ignored this role and the impact of its existence on women's equality of opportunity in the workplace (2001). Kessler suggests that a normative solution is needed to adjust this disconnect, because it is the ideological undervaluing of women's caregiving work that causes it to be overlooked and underaddressed in the workplace.

Complicating this literature on the overlooked private lives of women is the growing body of scholarship critiquing the active role that many work/life policies have played in further entrenching gendered roles. Fathering literature, in particular, has highlighted this critique, illuminating the problematic emphasis in institutional policies and culture on the need for women to have time to care for private needs, while men are expected to maintain their public identities without giving attention to private ones. As the fathering literature demonstrates, men are not only increasingly interested in being more involved in the development and raising of their children (Brandth and Kvande 1998; Doucet 2004, 2006; Wall and Arnold 2007); they can also 
make distinct and important contributions to child rearing (Doucet 2004, 2006; Featherstone 2003). Other studies have demonstrated the challenges that specific public policies and institutions pose to rectifying the imbalance of caretaking due to their contribution to perpetuating gendered identities (Hobson 2002; Jesmin and Seward 2011; Haas and O'Brien 2010; McKay and Doucet 2010).

The policies that have resulted from this historical and contemporary connection between women and caregiving roles, therefore, have emphasized the need to give women time away from work to care-give. This ideological connection is so strong that even when men are granted equal leave time for caregiving, women are still much more likely to take the time than men. According to the Bureau of Labor Statistics, women were thirty times more likely (3.2 percent of women taking leave, compared with .01 percent of men taking leave) to cite birth or adoption of a child as their reason for taking leave in any given week in 2011, even though they were only 3 percent more likely than men to take leave from work overall (U.S. Bureau of Labor and Statistics 2011). ${ }^{4}$

Not only is the construct of the ideal worker gendered, but it is also racialized. While white women struggle to meet the expectations of an ideal worker, they more easily meet the expectations of the ideal mother than women of color. Intersectional experiences of working mothers, therefore, lead to complex and contested issues that are often masked by homogenized discussions of "women and work" that often assume a white subject. Heather MacPherson

\footnotetext{
${ }^{4}$ It is worth noting, however, that men were 1.4 times more likely than women (2.6 percent of those taking leave, compared to 1.9 percent of women taking leave) to cite child or elder care (other than for illness) as their reason for taking leave.
} 
Parrott, for instance, demonstrates that white women have a larger "motherhood penalty"5 than women in other racial and ethnic groups. Parrott posits that this increased effect is due, not to white women's greater oppression in the workplace, but rather to greater variation in their ability to conform to the ideal worker construct. "Motherhood may not further depress wages simply because their wages are already too low. These findings suggest that theorizing about the motherhood penalty and gender inequality may have limited applicability to minority women experiencing double jeopardy in the workplace" (Parrott 2014). In other words, the ideal worker may be attainable for white women without children, but it is already unattainable for women of color, regardless of their parental status. Policies such as maternity leave, therefore, are designed with a particular image of white motherhood in mind. The connection of this imagery to public policy, argues Parrott, is unhelpful for white women who experience large "motherhood penalties" but also fundamentally unhelpful to Black and Hispanic women who would benefit far more from policies that aim to address racial and ethnic inequalities in wages and equal opportunity of employment.

This continued connection between the ideology of domesticity and public policy has unforeseen consequences for the experiences of all women hoping for workplace equality. Let us turn to the interview data to discuss ways in which the ideology of domesticity - and the ideal worker norm - have had a significant impact on the rights consciousness and rights claiming of women in both public universities and the U.S. military. Women who participated in this study identified two distinct workplace stereotypes tied to the ideal worker norm, and we will see the ways in which these women wrestled with the stereotypes when thinking through their rights.

\section{Case Selection and Methods}

\footnotetext{
5 This is a term that is used to refer to the phenomenon that occurs when working women have children and experience a greater gap in their wages compared to women without children. This "penalty" increases with the birth of each child.
} 
Numerous scholars who look at rights claiming in the workplace have already highlighted the significance of institutional context in influencing rights consciousness and rights claiming (Marshall 2005; Albiston 2005, 2010; Reese and Lindenberg 2003; Zippel 2004; Munkres 2008; Seron et al. 2004; Hoffmann 2001). Yet these studies do not undertake a comparative analysis of institutional contexts. This paper therefore makes a conscious comparison of workplace contexts. This comparison allows me to make broader claims about the significance of discourse within institutional contexts, and its impact on rights mobilization.

Additionally, I choose to compare academic institutions and the U.S. military because each of these types of workplaces offers unique characteristics and cultures, which are also generally transferrable across specific institutions. For instance, the culture of academia may be said to transfer from university to university, and the culture of the U.S. military may be said to transfer from branch to branch, base to base. While each institutional site will have its own flavor, it is possible to make generalizations about the culture of these professions as "institutions", while capturing a broad range of individual participants. Furthermore, both academia and the military have "cultures" that have been documented to be deeply entrenched (E.g. For the academy, see: Mason et al. 2013; O’Brien Hallstein and O'Reilly 2012. For the U.S. military, see: Enloe 2014; Taber 2011, 2013). Since workplace culture is the primary focus of this study, these sites are ideal for exploring the questions I tackle in my work.

This paper draws on data from 48 in-depth interviews that I collected over a one-year period from 2012 to 2013. Twenty-four of these interviews were conducted with academic faculty, and twenty-four of them were conducted with former and active duty service members from various branches of the U.S. military (Army, Navy, Air Force and Air Force reserves, Marines, and Coast Guard). The ages of the women interviewed range from 23 to 58. Some of 
the women who participated do not have children, but are thinking about becoming pregnant or adopting in the near future. Other participants have one or multiple children. Additionally, the levels of career achievement (and consequently income levels) vary widely among the women interviewed. Among military women, fifteen of the women are enlisted members in ranks ranging from E-3 to E-7, and nine of the women are or were officers, with the highest rank represented being a current colonel in the Air Force. Among faculty women, I spoke with fifteen women at a small public university in the south, and nine women at a large, multi-campus university in the northeast. Twelve women are visiting assistant professors still on the tenuretrack, four women are tenured associate professors, and six are adjuncts, instructors, or visiting assistant professors. Among all of the participants, race, ethnicity and sexuality does not vary considerably. Only three participants identified as "non-white" and only one participant identified herself as being in a same-sex relationship. Most of the participants are married or living with a partner, with only six identifying as single or separated. Finally, ninety percent of the women interviewed also identified themselves as either the primary breadwinner or "equal" in regard to wage earning in their households. ${ }^{6}$

Each woman interviewed was asked the same series of loosely organized questions about her experiences with taking maternity leave at her place of work, which included questions about her experiences with planning to have children, pregnancy and/or adoption, taking leave, finding information about policies, returning to work, and interactions with colleagues and/or supervisors regarding work/family issues. Each interviewee was also asked a series of questions about her opinions regarding maternity leave in the U.S. and at her place of work, and about how

\footnotetext{
${ }^{6}$ Only one-third of the women in this study identified as being the primary breadwinner in her household. On a national level, by comparison, $40 \%$ of all households with children under 18 include mothers who are the sole or primary breadwinner. (Wang et al. 2013). However, the majority of women in my study (22 out of 48) responded that they and their partner were "equal" breadwinners, which masks minor income differences that may bring my sample closer to the national average.
} 
she might like to change policies if at all. These questions were all covered in each interview, however the format and structure of each interview was unique, and certain follow-up questions differed based on each individual's related experiences.

In analyzing the interview data, I used interpretive methods to explore women's use of legal or rights-based language, and their formation of concepts and justifications for their actions in relation to the policies to which they are entitled concerning work/life balance. The choice of interpretive methods over something like content analysis here is appropriate, in that I was interested in a bottom-up development of concepts, rather than mapping pre-existing terms and models onto these women's language and consciousness. Since I am interested in how women think about and interpret public policy, it was appropriate to use a method that would allow for inductive techniques for determining how women's knowledge of and interaction with these policies has been influenced (Schwartz-Shea and Yanow 2012). I conducted each interview myself, making note of major themes addressed at the time. I then reread each interview multiple times, noting major themes that emerged consistently throughout each case study. Finally, once I had identified several of the major themes I wanted to address in the analysis, I systematically coded each transcript for these themes.

\section{Mothers Are Not Ideal Workers}

Literature on both academia and the U.S. military documents to some extent what is expected of an ideal worker in these environments. In academia, for instance, faculty are expected to pursue tenure-track careers that lead to full professorship, which most often requires a grueling research and teaching schedule. These expectations are frequently coupled with an understanding that faculty must not have commitments that take their time and attention away from these 
expectations, particularly the research element. Recent studies of male and female academics, for instance, have demonstrated that the individuals in these careers who are most successful at maintaining a high level of research output are married men with children and the least successful are married women with children (Townsend 2013; Krapf et al. 2014). These findings further emphasize the significance of unpaid domestic work in the ideal worker construct. Married men with children are successful, the authors of these studies suggest, because a female partner either fully or largely completes the "second shift" of housework and child care within the home, allowing them to devote more time to their primary career. Married women with children are, conversely, doing a disproportionate share of the domestic work and are thus disadvantaged in the time they are able to devote to paid work (Hochschild 2001; Hochschild and Machung 2003; Mason et al. 2013; Townsend 2013; Krapf et al. 2014).

In the military, the ideal worker is much more overtly masculine. As Cynthia Enloe notes, masculinity and the U.S. military are intimately connected. The ideal worker in the U.S. military is a "warrior"-specifically, one who is male (2014). Yet in a volunteer military, recruitment of women soon became necessary in order to sustain its numbers. In opening the military to women, Enloe argues, officials "believe that they need to recruit and deploy women in only those ways that will not subvert the fundamentally masculinized culture of the military" (2014, 37). A woman in the U.S. military, therefore, is not an ideal worker simply by virtue of being female. Pregnancy and childbirth complicate this by reminding a woman's colleagues and superiors of her femaleness in very explicit ways. In both the U.S. military and public universities, my interviews demonstrate that institutional stereotypes have developed around women with children in these workplace settings as individuals who do not—and cannot—meet the expectations for an ideal worker. 


\section{The Military Mother Who Is Avoiding Deployment}

In my interviews with military servicewomen, it became clear very quickly that a stereotype existed, and each of the women I spoke to was in some way reacting to it. In all but one of the interviews, the service member identified the stereotype explicitly. Essentially the stereotype is that women who become pregnant in the military do so in order to avoid her duties as a warrior in some way, though the duty most frequently referenced was overseas deployment. Mothers in the U.S. military therefore do not fit the ideal worker image in their workplace because the ideal worker in a military environment is one who is physically fit and always ready to do his or her duty when called on. A pregnant service member does not fit this model in that she receives "special treatment" - which includes deferral from deployment for four to twelve months after childbirth $^{7}$ and exemptions from other typical duty requirements, such as uniform regulations or physical training exercises.

In detailing what the stereotype is, many of the women I interviewed were also careful to identify themselves as individuals who do not fit the stereotype. Grace, a thirty-three-year-old sergeant first class in the Army, clarified that she was aware of the stereotype but that she wasn't deployable when she got pregnant:

I mean there's a little bit of a stigma for people — especially women — that are staying behind [from a deployment].... It's "Oh, did she get pregnant to get out of deployment?" I mean—which, I'd been pregnant before it was even known that we were

\footnotetext{
${ }^{7}$ The length of time depends on the service branch and whether the mother is breast-feeding. The Air Force recently expanded this time to twelve months for breast-feeding mothers, but at the time the interviews were conducted, the women in this study were eligible for four to six months of postpartum deferral. In early 2016, the Pentagon announced that all branches would now extend their maternity leave to 12 weeks for women and 14 days of paid leave for fathers (Ferdinando 2016).
} 
deploying, but there's still always that little bit that, you know, the possibility of that chatter ... it's more-I think, more of a gossip thing."

Grace goes on, however, to point out that she knows another woman who might better fit the stereotype:

[A soldier under my supervision] was actually in Afghanistan when she found out she was pregnant. ... From the view of the command, they were not out to do her any favors. You know, she got sent home; technically she could have been punished. I mean, it didn't happen, but it definitely leaves a bad taste in the command's mouth in a situation like that.

Similarly, Joyce, fifty-eight, currently serves as a colonel in the Air Force. As a captain, she left active duty for the reserves when she decided to start her family and reentered only when her children were school age. "I separated [from active duty] what, a year and a half before the war [in Afghanistan] kicked off, so it wasn't like I did it because I had to go to war," she explains, clearly indicating her knowledge of the stereotype and her own position outside its reach. She continues, though, to relate that

a friend of mine was in a similar situation only she delivered her baby in August of $1990 \ldots$ and her husband was already deployed to Desert Shield, and when she came back to our squadron, which is a deployable squadron, a flying squadron, she went over to a nondeployable squadron.... and people talked about that. Even years later people talked about that, how she was given special treatment or that she didn't do what she should have done, which was deploy. 
Sophia, a twenty-three-year-old third-class petty officer in the Navy, had a harder time defending her position in relation to the stereotype. Sophia, who is not married, became pregnant unintentionally while on a deployable ship and had to leave her boat for shore duty as a result. She insists that she is not one of the "girls who mess up" and "put a stigma on all the rest of the pregnant girls." Yet she felt as though she needed to hide her pregnancy from her fellow sailors when she left her ship, fearing that they would think she fit that stereotype:

There were a few people like that, they were like, ah, yeah, I see what you're doing, you know. And I kind of tried to keep it really quiet that I was pregnant when I was leaving. I told a lot of people I was leaving because of a bad back. So I didn't want to be known as that girl who got pregnant or got knocked up and had to leave the boat.

Many of the servicewomen who were interviewed also went beyond simply mentioning the stereotype and defining themselves in opposition to it. A number of them also said that their decision making, or that of other women they knew, has been influenced in whole or in part by the existence of this stereotype. For instance, some, like Gina, a chief petty officer in the Coast Guard, said that they consciously tried to work harder than their colleagues as a way of combating the image. Gina says:

I feel like already because we're females we have to work twice as hard to earn the respect that the males are already given, and then when you have these impressions running around in everybody's minds, and then it just—it spurs me on even more. I moved up pretty quick in my advancement, and a lot of that is just my initiative and my drive to prove people wrong. I'm tired of hearing it.

Adrienne, a thirty-eight-year-old Air Force major, took a similar though slightly different 
approach to combating the stereotype. During her pregnancy, Adrienne took pride in doing tasks that were above and beyond those recommended by her military profile. ${ }^{8}$ She talks about meeting wounded warriors on the flight line right up until delivery, and also braving a massive snowstorm to go into work at eight months pregnant because she knew she would be able to get there before her supervisor to make sure that her work was being overseen at a critical time. She says she made these decisions because "I just didn't want them to appear that I was using my profile to get out of work" - and that she was "just doing what you're supposed to do as a leader." She says of her profile:

I think it recommended like you not stand for so many—-for such a period of time or something like that —and then it allows you to wear tennis shoes if you wanted. Which is another thing: I never wore tennis shoes. I was so proud not to wear tennis shoes my whole entire pregnancy. I wore my boots - my combat boots the entire pregnancy. I guess I just didn't want them to think because I was on profile I was taking the easy way out.

Adrienne takes pride in wearing her combat boots while pregnant and performing other tasks that she would be within her rights under military regulation to forgo. In this way, she is signaling to herself and to others that she is an ideal worker. She does not fit the stereotype but rather is eager to show others that she does not need to claim her rights as a pregnant member of the Air Force. Adrienne's behavior reflects a consciousness that rights claiming would make her stand out as nonideal.

\footnotetext{
${ }^{8} \mathrm{~A}$ profile is a system used by the military to determine what a service member should be expected to do mentally, physically and medically for certain jobs and for their particular circumstances. A pregnancy changes an individual's profile temporarily.
} 
Like Adrienne, Liv, too, was quick to adopt behavior that would help her to stand out as an ideal worker in her new unit, stating her willingness to deploy earlier than required postpartum. Liv is a twenty-six-year-old Army sergeant in an airborne unit who, at the time of our interview, had an eight-month-old baby. When Liv found out about her pregnancy, her unit had just returned from a deployment. "There is no good or bad time to get pregnant in the Army," she says, but notes that "I was kind of in a good position because I did just get back from a deployment, so it's not like I looked like I was getting pregnant to get out of deployment." When asked whether this impression concerned her, Liv replied, "I mean, it's always in the back of your mind.... You know, my sergeant ... one time, you know, I went to the motor pool to go and help and he goes, 'Ah, get out of here, you're useless,' . . and I mean he was just joking, but he was also kind of like, you know, 'You can't do anything for me because you're pregnant,' so there is a stigma that's attached to it."

When Liv was transferred to a new unit early in her pregnancy, she had to confront the stigma head-on, since this new unit was due to deploy soon and was not the same unit with which she had recently returned from deployment. Liv says that she was so worried about how being pregnant would look in this situation that she offered to waive her postpartum period of deferred eligibility for deployment:

When I actually met the battalion commander... he said, "Oh you getting ready to deploy with us?" and I said, "Welll sir, I'm pregnant, you know, and I'm due in February," and at that time, they weren't supposed to deploy until a little bit later, so I said, "I could waive my postpartum time and I can deploy with you guys," and you know, he was all for that. He doesn't have any children.

Liv's immediate supervisor, a sergeant major, however, stopped her from doing this. "He said 
that he wouldn't allow me to waive my postpartum time to meet them in Afghanistan.” Nevertheless, Liv's concern about how her pregnancy would look to her new lieutenant colonel and her fellow soldiers was concerning enough to her to consider relinquishing her right to defer deployment. For both Liv and Adrienne, waiving their rights to work/life balance policies aimed at improving their conditions in fact became a way for them to mark themselves as ideal workers.

Not all of the servicewomen felt that their decision making due to the stereotype was a way to combat it. Some of them said that they knew that a lot of their colleagues simply accepted that children and the military do not go together. Gabrielle, a thirty-six-year-old lieutenant colonel in the Air Force says, "A good number of us [mothers in the Air Force] will punch" [leave the military altogether] at that ten-year point. Because at that point in time, you've either gotten married or you haven't and you want to, and you've had children and you're trying to balance and it just_-something's gotta give basically." Women who leave the military after ten years of service lose out on significant benefits and compensation that can be attained only after twenty years of service. The existence of the stereotype, Gabrielle believes, causes many women to think that balancing a military career and family is simply not possible and so they leave, meaning that women are much scarcer in the higher ranks, where length of service is a prerequisite. This trend in the military is strikingly similar to the problem of the "leaky pipeline" in academia, where women are also largely underrepresented at the higher ranks (Mason et al. 2013; Wolfinger et al. 2009; Krapf et al. 2014).

While not all of the servicewomen interviewed felt that they had been especially harmed by the existence of the stereotype, a few did. Zoe, a 29-year-old veteran who had served in the

9 "Punch out" is slang for ejecting from a military aircraft. 
Air Force for three and a half years, cited the stereotype, and her supervisor's reaction to it, as the reason she decided to take the option offered by all branches of the armed forces - to leave service with an honorable discharge during pregnancy. Zoe says when she found out she was pregnant and would be a single mother, she had never intended to leave her career. "I knew that it was gonna be a stressful experience, but I also knew that I was gonna have my schooling paid for, and that I would rise up in the ranks, and that this was what I had wanted to do since I could remember." She says, though, that she decided to get out when a supervisor approached her after learning of her pregnancy, and threatened her.

"[T] he new NCOIC said to me, 'mark my words, when you get back, as soon as your son is six months old, I'm deploying your ass.' And I was like, what? Oh - what? And he was like, 'yeah. You said you wanted to go on TCNs, and deployments and all this kind of shit when you got here. You're leaving when your son's six months old, so get your little family care plan together.",

Six months postpartum is the earliest that women in the Air Force are required to be eligible to deploy again. ${ }^{10}$ Zoe insists that she knew she would potentially have to deploy, but that it was the fact that her supervisor had made her feel as though she would be specifically targeted because he perceived that she was trying to get out of it that made her start to think about leaving.

"You know, I knew that it was a possibility... like my bucket comes up, or whatever, I want to go...but it would have been vastly different, because I knew the intention isn't to

\footnotetext{
10 That was the case at the time of my interview with Zoe. It is worth noting, however, that the Air Force changed its policy in 2012 to extend this time period to twelve months post-partum for breastfeeding mothers. Until recently, the Army required post-partum mothers to be eligible to deploy as early as four months after giving birth. (http://breastfeedingincombatboots.com/military-policies/)
} 
separate me from my child. You know, and that was his intention. And to cause me kind of like undo, you know, stress."

Even when more formal consequences are not evident, some of the women claim that the effect that the stereotype can have on relationships, with both their chain of command, and their colleagues, can also be significant. Brianna, a thirty-four-year-old Army specialist with two children, whose husband is also serving in the Army, felt personally targeted because of the existence of the stereotype about mothers in the military. She says that not long after having her first child, she was deployed to Kuwait. "Little did I know, I was pregnant with my daughter. ... [My] first sergeant was irate. She was livid. She told me I should be a housewife. That the Army isn't for me. I'm a substandard soldier. She gave me forty-five minutes of what she thought about me being pregnant." Brianna said that she felt particularly hurt by being a target of this first sergeant, because prior to this incident, she had looked to her as a mentor for how to become a strong female leader in the military. "She really got in my head, she really messed with me.... I joined the military to serve my country. I come from kind of like a rich background of military in my family. And so for me to deploy, I was very proud. ... So a lot of me felt like I let my unit down, I let myself down, I let my family down.” Their relationship remained strained, and Brianna was relieved when she was later transferred and no longer required to work with that supervisor.

It is clear that the stereotype of a mother in the military who gets pregnant to avoid deployment or in other ways "shirk" her duty is one that stands in direct contrast to the "ideal worker" notion of the service member who is always ready to do their duty. Yet it is also important to note at this point that the very policies aimed at recruiting and retaining mothers 
who serve may be directly feeding into this stereotype. By keeping female service members from deployment, allowing them time away to breastfeed, and time away from other requirements such as uniform codes and PT exercises, these "family friendly" policies serve to offer confirmation of the existing stereotype (or perhaps even fed its creation) - that military mothers are not ideal workers.

\section{The Academic Mother Who Is Not a Serious Scholar}

Women faculty working in public universities identified a stereotype with features unique to academia but nonetheless strikingly similar to that faced by U.S. military servicewomen. Most of the women interviewed referred to an explicit stereotype: that women who have children at an academic institution are not serious scholars. In addition, the minority of these women who did not explicitly reference a stereotype still talked about how having a family could cause them professional difficulties, but their discussion of this tension was more implicit.

Some of the women faculty referred to interactions with colleagues in their workplaces where the stereotype and how to counteract it were discussed outright. Valerie, for instance, a visiting assistant professor with a two-year-old son, discusses how this stereotype was related in stark terms to her by another female colleague:

It was like Labor Day or something, that we had classes, but none of the local public schools had classes. A couple of the parents brought their kids to the office. But I did have someone tell me-I didn't bring my son—but I did have someone tell me, you know, “As a woman I wouldn't do that if I were you. People have trouble taking moms seriously, and they won't take you seriously if they see you walking around with your son. They won't think you take the job seriously." 
Carol, a thirty-nine-year-old associate professor with a young child, says that she also had an interaction with a colleague that made her aware of the stereotype.

[My colleague] is a woman who is not—does not have a partner and does not have kids, and... she is a person who- the excessive energy around - "Oh let's talk about your kids, oh it's so exciting that you're pregnant"-felt suspicious to me.... I mean, it was very nice of her ... but I just remember feeling like she was wanting to peg me as, okay, now she's a mom. Like, she's not really a scholar, she's a mom, and so I'm gonna talk to her in a baby voice about the kids.... I don't think that this was intentional. I don't think that this was, you know, some sort of consciously hostile thing. But it felt to me like I'm being stereotyped.

Overall, the women employed at the public universities seemed less concerned than the servicewomen had about needing to distinguish their own position outside the stereotype. Though some women, like Carol, indicated that they have made conscious choices to avoid being stereotyped, not every individual interviewed made this distinction as starkly or as comprehensively as the servicewomen did. Furthermore, none of the female faculty felt a need to point out that while she did not fit the stereotype, other female faculty did. Instead, the faculty who identified the stereotype explicitly went on to deny its validity.

Nonetheless, each woman interviewed discussed the difficulties that she had faced in trying to be do her job well while balancing it with her family demands. Therefore, the phrase work/life balance (and a concern for achieving it) was a consistent theme across these interviews. What seemed to be a trend among academic women was to discuss the choices that they had made in response to these demands. Many of the female faculty interviewed said that their knowledge of the stereotype had caused them to feel conflicted or anxious about navigating 
work/life balance policies. Additionally, some faculty admitted that a consciousness of the stereotype had some serious effects on their decision making. Therefore, while female faculty members, on the whole, were not as willing to openly acknowledge that the stereotype correctly characterized some women in their profession as the servicewomen were, they nevertheless struggled to define themselves in opposition to it, indicating its significant impact on their rights consciousness.

Several of the academic women, like the servicewomen, talked about feeling the need to work harder to counter the narrative that they are somehow shirking their duties. Louise, for example, an assistant professor at Oak University with four children, says that she feels anxiety about appearing to be a good worker. "I mean ... I don't want people think that I'm just cashing it in—taking advantage of people's goodwill." Louise talks about feeling guilty for not making her time on bed rest with her latest pregnancy count more in terms of working toward her publishing record. "I mean, I read tons of stuff online, you know . . . like, everybody dreams of having seven weeks where you're sitting on your bed doing nothing but that . . but it doesn't ever work out that way." Louise goes on to say that even though she worked on article revisions and read during this time, and despite being "on track" with her publication record, she felt that "I lost that summer."

Additionally, Vicky, a mother of two at Elm who is in her forties, says that she worked from home during her entire maternity leave with her second child:

I was one of those really awful people who knew that they could take the time away, but would sit on the computer and do the work. Because [my son] had been born ... early, I hadn't finished some of those projects that I was supposed to finish, I felt really compelled to do them, and so a week after he was born I was probably getting back on 
the computer and trying to do the work.

These stories are consistent with a recent national study of U.S. mothers, which reported that 43 percent of women surveyed did at least some work for their employer while on maternity leave (Declercq et al. 2013).

Other academic mothers felt that they had to make some difficult personal choices in order to respond to the stereotype. Constance's story, for instance, provides a clear example of engaging in personal sacrifice to conform to ideal worker norms. Constance is a thirty-nine-year-old assistant professor in her first year of a tenure-track position at a small public university in the American South. While on the academic job market in the year prior to our interview, Constance admits to having struggled with whether to get pregnant. "I'm probably in a little bit of an unusual situation because of my age. . . . We've had some difficulty—not getting pregnant, but I had some losses, so I knew I was going to have to start work pregnant." When I spoke with her, Constance had just given birth. She says she timed her pregnancy so that she would give birth during the summer months, thereby hoping to avoid any impact on her teaching. This timing was also important because "I knew, because I had calculated all of this out, that I would not have maternity leave or modified duties because I hadn't been employed here for a year. . . I thought maybe they would kind of swing it, or maybe they would help me out with something, but I didn't know, and so that's why I had to-I timed it so I would have the baby in summer."

Constance says that she struggled considerably with the implications that starting a family would have on her career. She recounts feeling the dual pressure of trying to become a first-time parent at her age while at the same time starting a new job. Constance says she felt comfortable trying to get pregnant only in the window of time that would have allowed her to 
have her baby in the summer before she started her job, because "I was worried about how it would look at my job. ... I mean, I am a good worker, right? I'm a responsible person, and I didn't want to start off on ... what seemed like they would think of as an irresponsible thing." Terrified of becoming pregnant at the "wrong" time in her career, Constance chose to undergo physically demanding hormone therapy in order to conceive within a certain window of time.

Marie, too, made a personal choice that for her was extremely difficult. Marie is a thirtyone-year-old visiting assistant professor who does not yet have children and is waiting to do so until she secures a tenure-track job. She feels that the stereotype is particularly acute for her as a visiting assistant professor. Although she wants to ask about policies available to her, she says, 'It's this question you're told you cannot ask because it'll work against you in the job evaluation, and they'll assume that you're about to go out and have a whole litter of babies, so-yeah, I feel very silenced about [it]. I couldn't ask if just in case, what are my rights, how would you handle it — nothing." In addition to this tension, Marie also feels conflicted because she is a Catholic and until recently was not using birth control. As a married woman, Marie faced a potentially impossible situation: "The choice I was looking at was not so much contracept as not contracept, although that was my solution. The choice I was looking at is abortion or my career . . that's not a choice." ${ }^{11}$ Marie made a difficult decision for her to go against the teachings of her religion and use birth control in order to counteract the stereotype that she faces in her career.

Most commonly, however, the academic women who were in faculty roles mentioned making career sacrifices in order to be able to better balance the demands of their jobs and the

11 Both the use of contraception and abortion are forbidden under the teachings of the Catholic Church. Marie chose to use contraception because she felt that if she were to become pregnant, she would have to give up her career because the constraints of being a mother in academia would be too great. Additionally, because of her religion, abortion is an unthinkable option for Marie. 
demands of their families. This decision seems to be a way of trying to take ownership of the stereotype and nullify its significance by discussing it in terms of personal choice. Alex, for instance, says:

Yeah, I think at some point I decided, am I going to be the most aggressive publisher in the world, or am I going to be okay with not being the most aggressive publisher in the world, and spend more time with my kids? And I made that decision, and, you know, I was a little worried. I did fine with tenure-I was a little worried with tenure, I think everybody is - but I certainly at that point, when I was turning in my packet ${ }^{12}$ I was like, I wish I had, you know, been a little bit more productive at least, you know, somewhere in there. But at the same time, it was a decision I made.

Alex takes responsibility for her decision to make some career sacrifices to attain a better work/family balance. At the same time, the stereotype of her as someone who is not as serious about her career seems to have caused her some doubt about her choices when she was going up for tenure. Therefore, although her personal decision making was a way of voicing her autonomy from the stereotype, she was not entirely able to escape its power to cause her anxiety.

As was the case with the servicewomen, not all of the women faculty members interviewed said that they had felt personally targeted because of the stereotype. A few, however, did witness or experience personal attacks or discrimination because of their decision to have children. One assistant professor interviewed, who does not yet have children but is thinking about having them in the near future, was not affected herself, but she had a friend who she felt

\footnotetext{
12 "Packet" refers to the packet of materials a tenure-track professor is required to put together in order to support a case for tenure. These materials include published materials, teaching evaluations and other evidence of meeting the tenure criteria specified by the tenure-granting institution.
} 
had been targeted, and this experience made her wary of having children before tenure:

One of my colleagues went up for tenure, and she had stopped the clock, and she was just really, really worried about tenure, because — she ended up getting it, but I guess at her panel interview, what she told me was that people had said like, "You know, you had that whole extra year. What were you doing?" And she said, "Well, you know, I had an infant at home. I wasn't really_-I just didn't have the opportunity to focus on my research. It wasn't like a sabbatical year," and just even having to defend that just seems really shortsighted to me.

Other women felt more directly targeted. Danielle, a thirty-two-year-old visiting assistant professor with a young child, says that she felt singled out by a fellow faculty member while pregnant. Her job involves fieldwork, so she was frequently out in the field working rather than in her office. "I had a particular faculty member contact the dean telling the dean that I'm not in my office, that I'm not doing my job, because I'm not face-to-face. And so I got an e-mail that was forwarded from my dean, asking where am I, and I simply replied, 'I'm in the field."' Danielle expressed, like many of the other women interviewed, that she had been working extra hard during her pregnancy to make up for the fact that she was going to take time off. That was why this colleague's behavior seemed especially perplexing to her. When asked why she thought that colleague had targeted her to report to her dean, Danielle, who also identifies as African American, said, "She was very, very conservative in her beliefs, and [my] being at the time unmarried and pregnant, probably added to her personal views toward me." In Danielle's opinion, the institutional construct of the ideal worker reinforced and heightened other ideological constructs that this coworker held in her mind about who is a "good mother." Danielle thus found herself unable to meet the expectations of this colleague for either an ideal 
worker or an ideal mother.

Nora, a mother of two children, felt even more explicitly targeted because of the stereotype. Nora is an associate professor and administrator. When she was applying for an advanced administrative position a few years prior, Nora recounts that her interviewer said something surprising to her: "She said she was concerned about my ability to do the job because I had a child. ... So at that point in time I was like ... you've got to be kidding me." Nora was not chosen for the position. Nora says that she feels her job and the stereotype that exists in her place of work is counterproductive. "There's nothing enlightened about that." The first reaction when someone has or adopts a child, says Nora, "ought to be, 'Congratulations! How can we make it so that you can enjoy and have a healthy experience for you and your child, and then embrace you so that you come back to us ready to go,' and that's just never happened that I've seen.”

Eve, a thirty-three-year-old mother of two who is an assistant professor, said that she almost didn't to return to her job in the year that she was interviewed because of an experience where she had felt targeted as a mother at work. She said that at first, her supervisor and her colleagues had been excited and happy for her when she returned to work from maternity leave with her most recent child:

And then as we started to get into the evaluation process of my work, those conversations kind of started to change a little bit. Like my evaluation, my midtenure review. I started getting comments. I had my lowest annual review the year that I [took maternity leave], with the comment written that my personal life was affecting my work.... Comments being made perhaps I should consider getting a nanny instead of using child care if I wanted to be successful in my job. Have I ever thought about working part time, so that I 
can spend more time at home with my children? Comments like that from my colleagues and from my immediate supervisor that I was not expecting. ... It made me start to think that maybe I couldn't do it. Like, wow—maybe I can't be the mom that I want to be and be the professional that I want to be at the same time, and it really kind of started to weigh heavily on me, reconsidering my options for employment. Maybe I needed to go part time; maybe I needed to do different things. I almost didn't come back this year.

Paradoxically, when asked whether she personally felt that her performance at her job had suffered because of having her second child, Eve emphatically denied it: "No. Not at all. Not at all. I felt like I was able to balance it. I had a great support system at home, and so I thought I ... was doing fine. I really did. ... I actually felt — hey I can do this! Like, this is really manageable. So I was really surprised with the outcome.”

As with their counterparts in the U.S. military, policies aimed at recruiting and retaining academic mothers by offering to allow them to stop their tenure clock, and to take time away from their research and teaching duties, may in face be feeding into a pre-existing expectation (or helping to construct the expectation) that academic mothers are not ideal workers. In both public universities and the U.S. military, each of the women interviewed had either an explicit or an implicit understanding of the ideal worker norm as it exists within her institution. The expectations of their individual jobs are drastically different, but the ideological construction of gender identities, which set expectations on women that they should be primary caregivers and in charge of the domestic sphere, leads to similar expectations of an ideal worker within each workplace setting. Ideal workers are not meant to be focused on what is going on at home, and women in these workplace settings are constantly struggling with that expectation. These women are also often doing battle in their workplaces with stereotypes that expect them to underperform 
in their jobs because they have domestic commitments. Although each woman in this study combats these constructs and the larger ideologies behind them differently, it is possible to see a clear connection between the ways that ideal workers are conceived within these institutions. Larger ideological constructs such as the ideal worker therefore permeate workplace cultures and take on unique institutional flavors. Yet the core of the construct remains and clearly affects how women think about and act on their rights in these cases.

\section{The Role of Policy in Creating and Reinforcing Stereotypes}

Most sociolegal scholarship has treated stereotypes as norms that operate in the "shadow of the law," governing attitudes and behavior in ways that are not governed by the law or are norms that perhaps have grown out of an absence of law. Norms that exist in the shadow of the law may even be in conflict with laws or policies themselves. Catherine Albiston discusses the power of such stereotypes to regulate women's abilities to bargain for their rights under the Family and Medical Leave Act. She notes that

over time, the interconnected and mutually reinforcing systems of meaning among, and work have come to form an invisible cognitive framework that gives meaning to leave for family or medical purposes. In particular, seemingly neutral features of work, such as attendance and time invested in work rather than productivity, have come to define "good workers" (Albiston 2005, 17. See also Albiston 2010).

The narratives presented here illustrate the relevance of Albiston's observation in broader context. The power of normative constructs such as the ideal worker (and the stereotypes that emerge around them) goes beyond what is possible to regulate with policy. Attitudes and behaviors such as those described in this article may be discouraged by the policies in place in 
these institutions, but hearts and minds cannot be effectively changed by policies alone, and in fact cultural change must often happen before policies can be truly effective. Indeed, this is one of the fundamental points made by the critical legal studies movement: "Liberal rights rhetoric ordinarily fails to consider that fundamental social changes are necessary to allow people to exercise their rights" (Tushnet 1984; 1390).

While this observation alone is interesting and important, another significant finding emerges from this research. The opportunity for institutional comparison provided by these interviews - the ability to look at two very different workplaces, with very different policies and nonpolicy normative ordering — reveals connections that go beyond institution-specific norms. The stereotypes that are visible in the military and academia are all connected to values associated with being an ideal worker (with what is "ideal" having specific institutional characteristics in each case). Furthermore, the stereotypes that are present in these institutions indicate that mothers are being defined as antithetical to the ideal worker. They are in fact workers who shirk their responsibilities.

What is even more unsettling about these findings is that they indicate a close connection between the existence of institutional stereotypes of mothers and the policies aimed at protecting mothers in the workplace. Policies such as maternity leave, breast-feeding accommodations and duty, or uniform modification all offer important contributions to the health and well-being of mother and child. Yet the fact is that maternity and other work/family balance policies create a legal environment in which mothers are receiving exemptions from workplace duties that other workers are not entitled to. The stereotype in the military is that military mothers are trying to get out of deployment, an essential duty, potentially required of anyone at any time. While it may not be true that an individual is trying to avoid deployment, a pregnant woman or new mother 
does not deploy with her unit. Pregnancy or childbirth and the subsequent deployment deferral make mothers an exception to that duty, putting them in stark contrast to the ideal male warrior who is able to do his duty at any time. Likewise, in academia, faculty members must "publish or perish," and in many other ways are expected to demonstrate devotion to the job. Mothers are exempted from the expectations of their jobs in academia to have children, if only for a time, when they stop the tenure clock, or take six weeks or more of maternity leave that keeps them out of the office and exempts them from teaching and service requirements. Furthermore, though less observable in the data presented above, it is also likely that many women face intersectional stereotyping that makes these workplace stereotypes more or less relevant for them. For instance, the expectations around white notions of domesticity and "good mothering" may mean that women of color face a double stereotype - a situation in which, as working mothers, they are unable to meet the expectations for ideal workers or ideal mothers.

The stereotypes observed in this research are important to record and wrestle with, not simply because they hold power in and of themselves to shape attitudes and behaviors (often in negative ways) but they also reflect the inherent problems in the current structure of work/family policies themselves. Work/family policies may often be implemented without taking into account how an institutional culture might react, and begin to shape norms and attitudes around those policies. Indeed, through an examination of the ideological discourse in two workplace-specific cultures, it is evident that as long as workplace policies are structured to exempt mothers from work for family needs in ways that other workers are not permitted to be exempt (or do not ordinarily opt to be exempted), then mothers will continue to struggle against stereotypes that paint them as workers who are (intentionally or not) shirking their responsibilities.

The ideology of domesticity — and its pervasive ideal worker norm in the context of two 
specific institutions - is incredibly salient. The ideal worker norm operates within these institutional settings, taking on distinct institutional flavors that are either explicitly or implicitly referenced by all of the interview participants, indicating their internalization to some degree or another. Each participant reacted to these stereotypes in different ways, and rights-claiming was not uniformly affected by the internalization of these norms. However, what factors affect how these women gain legal knowledge about work/life balance policies in their workplaces becomes clearer. By understanding the pervasiveness of these norms, their origins, and how they are communicated within an institution and internalized by individuals, it becomes obvious that public policy, born within a particular historical and ideological context, can both assist with and complicate rights claiming.

\section{Conclusion}

This article presents a particularly difficult problem by critiquing a set of public policies that have been hard-won and are cherished by most U.S. women. Indeed, women in my interviews often cited the existence of work/life balance policies such as maternity leave and other "special accommodations" as having been essential to helping them stay in their jobs. Louise, an associate professor at Oak University, put it this way: "I needed those policies . . those policies saved my ass." Yet it is also clear from this analysis that the current state of work/life balance policies is inherently problematic. Such policies rely heavily on an ideology of domesticity that perpetuates norms of women's caregiving. The persistence of this ideology within institutional policy then reinforces that ideology within workplace norms and cultures, which also creates additional tensions for women to navigate if they want to claim these policies. This analysis begs a larger societal discussion about how policies might be better designed and implemented to take these ideological and structural complexities into account. 


\section{References}

Albiston, Catherine R. 2005. "Bargaining in the Shadow of Social Institutions: Competing Discourses and Social Change in Workplace Mobilization of Civil Rights." Law and Society Review 39(1): 11-50.

- 2010. Institutional Inequality and the Mobilization of the Family and Medical Leave Act: Rights on Leave. Cambridge: Cambridge University Press.

American Academy of Pediatrics. (2012). Breastfeeding and the use of human milk. Pediatrics, 129(3), 827-841.

Berns, Sandra. 2002. Women Going Backwards: Law and Change in a Family Unfriendly Society. Aldershot: Ashgate.

Brandth, Berit, and Elin Kvande. 1998. "Masculinity and Child Care: The Reconstruction of Fathering." Sociological Review 46(2): 293-313.

Bumiller, Kristin. 1992. The Civil Rights Society: The Social Construction of Victims. Baltimore: Johns Hopkins University Press.

Cohn, D'Vera, Gretchen Livingston and Wendy Wang, 2014, "After Decades of Decline, A Rise in Stay-atHome Mothers.” Washington, D.C.: Pew Research Center's Social \& Demographic Trends project, April.

Declercq, Eugene R., Carol Sakala, Maureen P. Corry, Sandra Applebaum and Ariel Herrlich. 2013. Listening to Mothers III: New Mothers Speak Out: Major Survey Findings. New York: Childbirth Connection.

Doucet, Andrea. 2004. "Fathers and the Responsibility for Children: A Puzzle and a Tension." Atlantis: Critical Studies in Gender, Culture and Social Justice 28(2): 103-14.

- 2006. Do Men Mother? Fathering, Care, and Domestic Responsibility. Toronto: University of Toronto Press.

Engel, David M. 1984. "The Oven Bird's Song: Insiders, Outsiders, and Personal Injuries in an American Community." Law and Society Review 18(4): 551-82.

Engel, David M., and Frank W. Munger. 2003. Rights of Inclusion: Law and Identity in the Life Stories of Americans with Disabilities. Chicago: University of Chicago Press.

Enloe, Cynthia H. 2014. Bananas, Beaches and Bases: Making Feminist Sense of International Politics. 2nd ed. Berkeley: University of California Press.

Ewick, Patricia, and Susan S. Silbey. 1998. The Common Place of Law: Stories from Everyday Life. Chicago: University of Chicago Press.

Featherstone, Brid. 2003. "Taking Fathers Seriously.” British Journal of Social Work 33(2): 239-54.

Ferdinando, Lisa. 2016. "Carter Announces 12 Weeks Paid Military Maternity Leave, Other Benefits.” DOD News. http://www.defense.gov/News/Article/Article/645958/carterannounces-12-weeks-paid-military-maternity-leave-other-benefits (accessed October 7, 2016).

Fineman, Martha Albertson. 1995. The Neutered Mother, the Sexual Family and Other Twentieth Century Tragedies. New York: Routledge.

Gilliom, John. 2001. Overseers of the Poor: Surveillance, Resistance, and the Limits of Privacy. Chicago: University of Chicago Press.

Gruber, James E. 1998. "The Impact of Male Work Environments and Organizational Policies on Women's Experiences of Sexual Harassment.” Gender and Society 12(3): 301-20. 
Haas, Linda, and Margaret O'Brien. 2010. "New Observations on How Fathers Work and Care: Introduction to the Special Issue-Men, Work and Parenting-Part I." Fathering 8(3): 271.

Haas, Linda. 2004. "Parental Leave and Gender Equality: What Can the United States Learn from the European Union?" In Equality in the Workplace: Gendering Workplace Policy Analysis, ed. Heidi Gottfried, and Laura Reese,183-214. Lanham, MD: Lexington Books.

Haltom, William, and Michael McCann. 2004. Distorting the Law: Politics, Media, and the Litigation Crisis. Chicago: University of Chicago Press.

Heilman, Madeline E., and Julie J. Chen. 2005. "Same Behavior, Different Consequences: Reactions to Men's and Women's Altruistic Citizenship Behavior.” Journal of Applied Psychology 90(3): 431-41.

Hobson, Barbara Meil. 2002. Making Men into Fathers: Men, Masculinities, and the Social Politics of Fatherhood. Cambridge: Cambridge University Press.

Hochschild, Arlie Russell. 2001. The Time Bind. New York: Owl book.

Hochschild, Arlie Russell, with Anne Machung. 2003. The Second Shift. $2^{\text {nd }}$ ed. New York: Penguin Books.

Hoffman, Elizabeth A. 2001. "Confrontation and Compromise: Dispute Resolution at a Worker Cooperative Coal Mine." Law and Social Inquiry 26:150-70.

Jesmin, Syeda S., and Rudy Ray Seward. 2011. "Parental Leave and Fathers' Involvement with Children in Bangladesh: A Comparison with United States." Journal of Comparative Family Studies 42(1): 95-112.

Kelly, Erin L., Samantha K. Ammons, Kelly Chermack, and Phyllis Moen. 2010. "Gendered Challenge, Gendered Response Confronting the Ideal Worker Norm in a White-Collar Organization." Gender and Society 24(3): 281-303.

Kessler, Laura T. 2001. "The Attachment Gap: Employment Discrimination Law, Women's Cultural Caregiving, and the Limits of Economic and Liberal Legal Theory." University of Michigan Journal of Law Reform 34:371-468.

Kessler-Harris, Alice. 2001. In Pursuit of Equity: Women, Men, and the Quest for Economic Citizenship in 20th-Century America. New York: Oxford University Press.

Krapf, Matthias, Heinrich Ursprung, and Christian Zimmermann. 2014. Parenthood and Productivity of Highly Skilled Labor: Evidence from the Groves of Academe. St. Louis: Federal Reserve Bank of St. Louis.

Marshall, Anna-Maria. 2005. 'Idle Rights: Employees' Rights Consciousness and the Construction of Sexual Harassment Policies." Law and Society Review 39: 83-124.

Marshall, Anna-Maria, and Scott Barclay. 2003. "In Their Own Words: How Ordinary People Construct the Legal World." Law and Social Inquiry 28(3): 617-28.

Mason, Mary Ann, Nicholas H Wolfinger, and Marc Goulden. 2013. Do Babies Matter? Gender and Family in the Ivory Tower. New Brunswick, NJ: Rutgers University Press

McCann, Michael W. 1994. Rights at Work: Pay Equity Reform and the Politics of Legal Mobilization. Chicago: University of Chicago Press.

Morgan, Phoebe A. 1999. "Risking Relationships: Understanding the Litigation Choices of Sexually Harassed Women.” Law and Society Review 33(1): 67-92.

McKay, Lindsey, and Andrea Doucet. 2010. "WWithout Taking Away Her Leave': A Canadian Case Study of Couples' Decisions on Fathers' Use of Paid Parental Leave." Fathering: A Journal of Theory, Research, and Practice about Men as Fathers 8(3): 300-20.

Munkres, Susan A. 2008. "Claiming 'Victim' to Harassment Law: Legal Consciousness of the Privileged." Law and Social Inquiry 33(2): 447-72. 
O’Brien Hallstein, Lynn, and Andrea O'Reilly. 2012. “Academic Motherhood in a Post-Second Wave Context: Framing the Conversation." In Academic Motherhood in a Post-Second Wave Context: Challenges, Strategies, and Possibilities, ed. Lynn O'Brien Hallstein and Andrea O'Reilly. Bradford, ON: Demeter Press.

Okin, Susan Moller. 1991. Justice, Gender, and the Family. New York: Basic Books.

Parrott, Heather. (2014). "Housework, children, and women's wages across racial-ethnic groups." Social Science Research, 46, 72-84.

Pew Research Center. 2015. Raising Kids and Running a Household: How Working Parents Share the Load. November. http://www.pewsocialtrends.org/2015/11/04/raising-kidsand-running-a-household-how-working-parents-share-the-load/

Quinn, Beth A. 2000. "The Paradox of Complaining: Law, Humor, and Harassment in the Everyday Work World." Law and Social Inquiry 25(4): 1151-85.

Reese, Laura A., and Karen E. Lindenberg. 2003. "The Importance of Training on Sexual Harassment Policy Outcomes.” Review of Public Personnel Administration 23(3): 17591.

Scheingold, Stuart A. 2004. The Politics of Rights: Lawyers, Public Policy, and Political Change. $2^{\text {nd }}$ ed. Ann Arbor: University of Michigan Press.

Schwartz-Shea, Peregrine, and Dvora Yanow. 2012. Interpretive Research Design: Concepts and Processes. New York: Routledge.

Seron, Carroll, Joseph Pereira, and Jean Kovath. 2004. "Judging Police Misconduct: 'StreetLevel' versus Professional Policing." Law and Society Review 38(4): 665-710.

Taber, Nancy. 2011. " $<$ th $>$ 'You Better Not Get Pregnant While You're Here': Tensions between Masculinities and Femininities in Military Communities of Practice." International Journal of Lifelong Education 30(3): 331-48.

- 2013. "A Composite Life History of a Mother in the Military: Storying Gendered Experiences." Women's Studies International Forum 37:16-25.

Taylor, Paul, Kim Parker, Wendy Wang, Richard Morin, Juliana Menasce Horowitz, D’Vera Cohn and Gretchen Livingston,. 2010 The Decline of Marriage and Rise of New Families. Washington, DC: Pew Research Center. http://www.pewsocialtrends.org/files/2010/11/pew-social-trends-2010-families.pdf.

Townsend, Robert B. 2013. "Gender and Success in Academia: More from the Historians' Career Paths Survey." Perspectives on History 51(1). https://www.historians.org/publications-and-directories/perspectives-on-history/january2013/gender-and-success-in-academia\# (accessed October 7, 2016).

Tushnet, Mark. 1984. "A Critique of Rights: An Essay on Rights.” Texas Law Review 62(8): 1363-1404.

Wall, Glenda, and Stephanie Arnold. 2007. "How Involved Is Involved Fathering? An Exploration of the Contemporary Culture of Fatherhood." Gender and Society 21(4): 508-27.

Williams, Joan. 2000. Unbending Gender: Why Family and Work Conflict and What to Do about It. Oxford: New York: Oxford University Press.

Williams, Joan C., and Holly Cohen Cooper. 2004. "The Public Policy of Motherhood." Journal of Social Issues 60(4): 849-65.

Williams, Joan, and Rachel Dempsey. 2014. What Works for Women at Work: Four Patterns Working Women Need to Know. New York: New York University Press.

Wolfinger, Nicholas H., Mary Ann Mason, and Marc Goulden. 2009. "Stay in the Game: 
Gender, Family Formation and Alternative Trajectories in the Academic Life Course." Social Forces 87(3): 1591-1621.

Zippel, Kathrin. 2004. "Implementing Sexual Harassment Law in the United States and Germany." In Equality in the Workplace: Gendering Workplace Policy Analysis, ed. Heidi Gottfried and Laura Reese. 183-214. Lanham, MD: Lexington Books.

\footnotetext{
1 This article is adapted from Chapter 5 of The Balance Gap: Working Mothers and the Limits of the Law (Stanford University Press 2017). Thanks to Johanna Hopper and the School of Interdisciplinary Arts and Sciences at the University of Washington Tacoma for support in the development of this article.
} 